\title{
Symmetric Supercapacitor Application of Electrochemically Exfoliated Graphene - Chitosan Hydrogel
}

\author{
Omer Sadak ${ }^{1 *}$ \\ 1*Ardahan University, Faculty of Engineering, Department of Electric and Electronic Engineering, Ardahan, Turkey, (ORCID: 0000-0001-6717-9672), \\ omersadak@ardahan.edu.tr
}

(First received 15 December 2021 and in final form 11 January 2021)

(DOI: $10.31590 /$ josat.1036869)

ATIF/REFERENCE: Sadak, O. (2022). Symmetric Supercapacitor Application of Electrochemically Exfoliated Graphene Chitosan Hydrogel. European Journal of Science and Technology, (33), 133-137.

\begin{abstract}
In this work, electrochemically exfoliated graphene-chitosan hydrogel was prepared by a crosslinking reagent. Then, a symmetrical all-solid state supercapacitor was fabricated using graphene-chitosan hydrogel. Surface morphology of as-fabricated graphene was investigated using SEM and TEM. After constructing the symmetrical all-solid state supercapacitor, the device showed a specific capacitance $\left(\mathrm{C}_{\mathrm{m}}\right)$ of $153.6 \mathrm{Fg}^{-1}$ at $1 \mathrm{mAg}^{-1}$ current density. A great capacitance retention after 1000 consecutive GCD cycles was observed with an over $97 \%$ of retention. The supercapacitor can carry a high energy density of $3.47 \mathrm{kWkg}^{-1}$, as well as a high power density of $102.07 \mathrm{Wkg}^{-1}$.
\end{abstract}

Keywords: Graphene, Hydrogel, Supercapacitors.

\section{Elektrokimyasal Olarak Eksfoliye Edilmiş Grafen-Kitosan Hidrojelinin Simetrik Süperkapasitör Uygulaması}

$\ddot{\mathbf{O} z}$

Bu çalışmada, çapraz bağlama reaktifi ile elektrokimyasal olarak pul pul dökülmüş grafen-kitosan hidrojel hazırlandı. Daha sonra, grafen-kitosan hidrojel kullanılarak simetrik bir katı hal süper kapasitör üretildi. Üretilen grafenin yüzey morfolojisi SEM ve TEM kullanılarak araştırıldı. Simetrik tamamen katı hal süper kapasitörünü oluşturduktan sonra cihaz, $1 \mathrm{~mA} \mathrm{~g}^{-1}$ akım yoğunluğunda spesifik kapasitansı $\left(\mathrm{C}_{\mathrm{m}}\right) 153.6 \mathrm{~F} \mathrm{~g}^{-1}$ olarak hesaplandı. 1000 ardışı döngüden sonra olağanüstü bir kapasitans tutulması, \%97'nin üzerinde bir tutma ile gözlemlendi. Süper kapasitör, $3,47 \mathrm{~kW} \mathrm{~kg}^{-1}$ yüksek enerji yoğunluğunun yanı sıra $102,07 \mathrm{~W} \mathrm{~kg}^{-1}$ güç yoğunluğu sağlama yeteneğine sahiptir.

Anahtar Kelimeler: Grafen, Hidrojel, Süperkapasitör.

\footnotetext{
* Corresponding Author: omersadak@ardahan.edu.tr
} 


\section{Introduction}

Supercapacitors, typically known as electrochemical capacitors, are energy storage devices with a higher energy density than traditional capacitors and a greater power density than batteries. Electrochemical capacitors have a superior characteristics such as a long life cycle, a quick chargingdischarging rate, and a reasonable manufacturing cost (Sadak, Prathap, \& Gunasekaran, 2019; W. Wang, Sadak, Guan, \& Gunasekaran, 2020). However, supercapacitors require further improvement for their low energy density compared to batteries (Borenstein et al., 2017; Sadak, Sundramoorthy, \& Gunasekaran, 2018; Udayan, Sadak, \& Gunasekaran, 2020). Therefore, the majority of current research efforts have been focused on building supercapacitors with high power and energy density. Transition metal-oxides, carbon-based materials, and electrically conducting polymers are now the most prevalent electrode materials for supercapacitors, and their performance is totally dependent on their electrode materials (Bose et al., 2012). Due to their simplicity of manufacture, natural abundance, and wide operating temperature range, carbon-based materials are being investigated extensively (El-Gendy, Ghany, El Sherbini, \& Allam, 2017). They may exhibit excellent cycling and electrochemical stability and high-power density as supercapacitor electrode materials, but because of limitations in the energy storage mechanism, they often have low capacitance performance (Liling Zhang et al., 2017). On the other hand, transition metal oxides as supercapacitors may display excellent specific capacitance due to faradic reactions during to the charge-discharge process, but lack of natural abundance, lowconductivity, short cycle life, high cost, and toxic nature limit their applications. (He et al., 2017; Sadak, Wang, Guan, Sundramoorthy, \& Gunasekaran, 2019). On the other hand, polypyrrole, polyaniline, and poly-3,4-ethlyenedioxythiophene are examples of conducting polymers with strong pseudocapacitive properties, but they suffer from low-rate capability (Hu et al., 2016; H. Wang, Lin, \& Shen, 2016). Thus, the most accepted approach to overcome these disadvantages of electrode materials is incorporating highly conductive carbonbased materials and intrinsically-conducting polymers or metaloxides (Wu et al., 2017). On the other hand, polymers with high ionic conductivity have been also tested as a platform for solidstate conductivity and it also acts as polymeric electrolyte (Cao et al., 2021). These new trend leads to forming supercapacitor electrodes with low-temperature tolerance, ultrahigh stretchability, and strong self-healing.

Because of graphene's outstanding features, including as large specific surface area, outstanding electrical and thermal conductivity, lightweight, excellent mechanical characteristics, and chemical stability, graphene and its derivatives for supercapacitor electrode material is being widely investigated. (Khalid et al., 2017; Lai et al., 2011; Xue, Zhong, Cheng, \& Wang, 2016). Therefore, many approaches have been established for cost-efficient and facile synthesis of graphene from graphite: mechanical cleavage, thermal decomposition, chemical exfoliation, and electrochemical exfoliation etc. (Bonaccorso et al., 2012; Sadak, 2021; Sadak, Sundramoorthy, \& Gunasekaran, 2017). Despite the unique advantages and various preparation methods, due to the strong interactions between $\pi-\pi$ electrons and van der Waals interactions, graphene sheets have the ability to create irreversible agglomerates or even reorganize themselves to make graphite. (Shan et al., 2009). Theoretically, e-ISSN: 2148-2683 when the entire surface of single-sheets-graphene is fully accessible to electrolyte ion, it shows excellent specific capacitance of $\sim 21 \mathrm{uFcm}^{-2}\left(\sim 550 \mathrm{Fg}^{-1}\right)$ (Ke \& Wang, 2016; Xia, Chen, Li, \& Tao, 2009). Still, due to agglomerates and restacking, the anticipated specific capacitance which is highly influenced by the surface area is lower than theoretical value (Ke \& Wang, 2016; Li Zhang \& Zhao, 2009). To achieve high surface area graphene and preventing agglomerates and restacking for a better electrochemical performance, various techniques have demonstrated including plasma-enhanced chemical vapor deposition (PECVD) growth of verticallyoriented graphene sheets (Mao et al., 2013), graphene hydrogels (Xu, Lin, Huang, Liu, et al., 2013), holey graphene framework (Xu et al., 2014), and inkjet printed graphene (Sollami Delekta, Smith, Li, \& Östling, 2017). Graphene hydrogels are one of these approaches that has been researched in past few decades (Bashir et al., 2021; Khazaeli, Godbille-Cardona, \& Barz, 2020). Interconnected 3D porous frameworks with enormous specific surface areas enables these graphene hydrogels for multidimensional electron transport as well as fast electrolyte ion diffusion (Xu, Lin, Huang, Wang, et al., 2013). They have been employed as binder-free electrode materials in liquid electrolytes and have shown substantially high specific capacitances, excellent rate capability, and outstanding cycling stability (Xu, Sheng, Li, \& Shi, 2010). These promising findings highlight the 3D graphene hydrogels' great potential in supercapacitor applications and inspire attempts to improve their specific capacitance without losing rate performance or cycle life.

In this study, a graphene-chitosan hydrogel was used in energy storage application for the first time. First, electrochemically exfoliated graphene-chitosan composite-based hydrogel was synthesized using a crosslinking agent. Then, a symmetrical all-solid state supercapacitor was constructed by sandwiching two fabricated hydrogels to test graphene hydrogels' electrochemical performance. The results revealed that the symmetrical supercapacitor has a maximum operating voltage of $1.6 \mathrm{~V}$ without any polarization. It also showed a high specific capacitance of $153.6 \mathrm{Fg}^{-1}$. The symmetrical supercapacitor also showed $97 \%$ cycling stability over 1000 consecutive GCD cycles. Moreover, in this study, a chitosanbased hydrogel was employed as electrolyte and stabilizer material.

\section{Material and Method}

\subsection{Materials}

The Graphite electrode was purchased from Graphitestore, Inc. (U.S.A.). PBS, chitosan, and glutaraldehyde was obtained from Fisher (NJ, USA) and were used directly as received. Aqueous solutions were made with deionized (DI) water $\left(18 \mathrm{M} \Omega \cdot \mathrm{cm}^{-1}\right)$ in all experiments, unless otherwise noted.

\subsection{Synthesis of Electrochemically Exfoliated Graphene}

Electrochemically exfoliated graphene was made according to our previously reported approach, with a few changes (W. Wang et al., 2020). Briefly, two graphite electrodes were employed as working and counter electrodes in an electrochemical cell which contains $0.1 \mathrm{M}$ of PBS solution at $\mathrm{pH}$ 7. Then, $+10 \mathrm{~V}$ was applied to the cell for $1 \mathrm{~h}$. After washing with DI water, the solution was further exfoliated with ultrasonication for $1 \mathrm{~h}$ which 
was then centrifugated for $30 \mathrm{~min}$ at $3000 \mathrm{rpm}$. The supernatant was then collected, and concentration of electrochemically exfoliated graphene was adjusted to $10 \mathrm{~mL}^{-1}$.

\subsection{Hydrogel Formation}

After preparing $10 \mathrm{mgmL}^{-1}$ of chitosan solution, a solution of graphene: chitosan (1:0.6 ratio) was prepared. After stirring for 1 hour, the mixture was ultrasonicated for 10 minutes at room temperature. For crosslinking graphene and chitosan, glutaraldehyde and the solution were treated with acetic acid. In a rectangular container, the solution was transferred, and it was quickly converted into a hydrogel. Then, hydrogels were kept into $1.0 \mathrm{M}$ of $\mathrm{H}_{2} \mathrm{SO}_{4}$ solution before assembling a solid-state supercapacitor.

\subsection{All-Solid-State Symmetric Supercapacitor Fabrication}

First, a filter cut into a rectangular shape and was soaked into 1 $\mathrm{M}$ of $\mathrm{H}_{2} \mathrm{SO}_{4}$ and then the filter paper was used as a separator. Next, the filter paper was sandwiched between two hydrogels and a rectangular shaped aluminum foil was attached to both sides of hydrogels via double-sided carbon tape. To form an integrated all-solid-state symmetric supercapacitor, $0.5 \mathrm{MPa}$ pressure was applied to both sides of electrode for 1 hour.

\subsection{Characterization}

A field-emission scanning electron microscope (FE-SEM) (Helios FIB/SEM 660) was used to examine the surface morphology of the samples at $5 \mathrm{kV}, 0.4 \mathrm{nA}$ and $4 \mathrm{~mm}$ working distance. Samples for FE-SEM were freeze-dried before testing. Surface morphology of samples were further analyzed with transmission electron microscope (TEM, Tecnai T-12). For electrochemical measurements, a $\mathrm{CH}$ Instruments 660D electrochemical workstation was employed. As an electrolyte, $1.0 \mathrm{M} \mathrm{H}_{2} \mathrm{SO}_{4}$ was used and electrochemical analysis (cyclic voltammetry $(\mathrm{CV})$ and galvanostatic charge/discharge (GCD)) were done at room temperature.

\section{Results and Discussion}

\subsection{Surface Morphology Analysis}

In Figure 1a, TEM image showed largely transparent mono/few layers of exfoliated graphene sheets which ranges 1 to 3 layers of graphene sheets, confirming the electrochemically exfoliation of graphite. After the hydrogel formation by mixing electrochemically exfoliated graphene sheets and chitosan in the presence of glutaraldehyde and acetic acid, the hydrogel was placed on a TEM copper grid and dried for testing and Figure 1b shows the hydrogel surface morphology.

Then, surface morphology of electrochemically exfoliated graphene sheets and as-synthesized hydrogel were analyzed via SEM. Figure 1c and 1d shows SEM micrographs of electrochemically exfoliated graphene at different magnifications. The wrinkled and curved characteristics of graphene are seen in SEM micrographs. Figure 1e and 1f show different magnifications of the cross-sectional view of the hydrogel. The SEM images showed porous structure of cut surface of the freeze-dried graphene-chitosan hydrogel. Because of its porous structure and lattice, as-fabricated hydrogel may serve as an ideal supercapacitor electrode and may provide quick electron transport, greater stability, and good cycle performance.
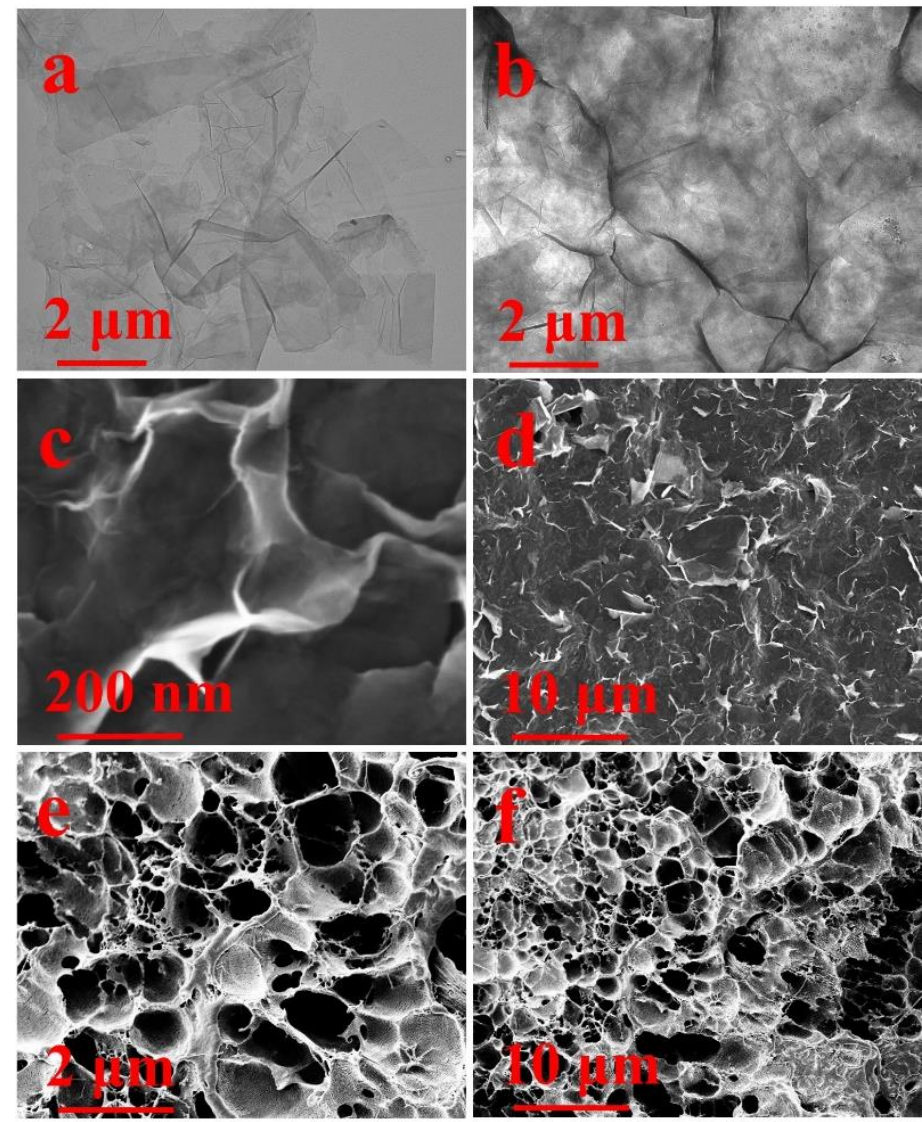

Figure 1. TEM images of (a) electrochemically exfoliated graphene sheets and (b) as-fabricated hydrogel. SEM images of (c), (d) electrochemically exfoliated graphene sheets and (e), (f) as-fabricated hydrogel at different magnification.

\subsection{Electrochemical Analysis}

To verify the stability and performance of the as-fabricated graphene hydrogel at varied working potentials, CV measurements were done in different potential windows from a fixed lower potential value $(0 \mathrm{~V})$ to higher potential values up to $2.4 \mathrm{~V}$ at $100 \mathrm{mVs}^{-1}$, as shown in Figure 2a. To achieve higher power density, the larger operating potential window is very desirable in electrochemical energy storage devices (Sadak et al., 2018). The results suggested that the operating potential windows are as large as $1.8 \mathrm{~V}$ without detectable oxygen evolution peaks or significant polarization. Figure $\mathbf{2 b}$ shows the graphene hydrogel's rectangle-like $\mathrm{CV}$ curves at different scan rates from 1 to $100 \mathrm{mVs}^{-1}$ which demonstrates excellent rate capability of as-designed all-solid-state symmetric supercapacitor.

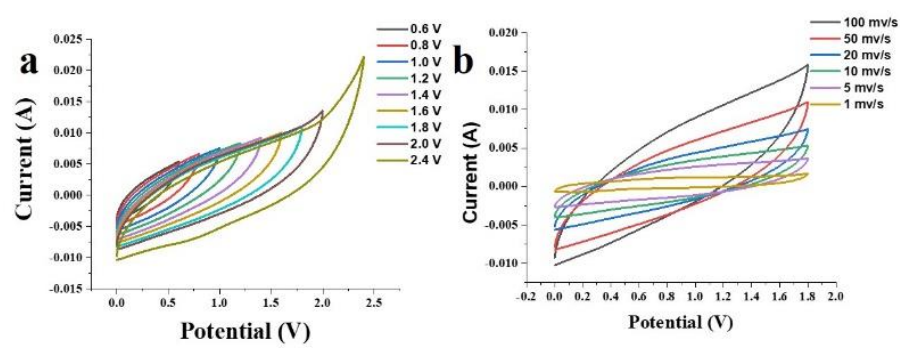

Figure 2. CV curves of the graphene hydrogel (a) at different potential windows and (b) different scan rates in $1 \mathrm{M} \mathrm{H}_{2} \mathrm{SO}_{4}$ 
The GCD curves were also done in different potential windows from a fixed lower potential value $(0 \mathrm{~V})$ to higher potential values up to $2.4 \mathrm{~V}$ at current density of $5 \mathrm{mAg}^{-1}$ as shown in Figure 3a. The results indicate highly symmetrical GCD curves up to $1.6 \mathrm{~V}$ which denotes a high degree of electrochemical reversibility. Under various scan rates $\left(1,510\right.$ and $\left.20 \mathrm{mAg}^{-1}\right)$, GCD curves of graphene hydrogel was obtained at a potentialwindows of $0-1.6 \mathrm{~V}$, as illustrated in Figure 3b. The GCD analysis results were employed to calculate specific capacitance $\left(\mathrm{C}_{\mathrm{m}}, \mathrm{Fg}^{-1}\right)$ based on the following equation (1):

$C_{m}=\frac{I x \Delta t}{m \times \Delta V}$

Where I represent the discharge current (A), $\Delta \mathrm{V}$ represents the discharge voltage range $(\mathrm{V}), \Delta \mathrm{t}$ represents the discharge time $(\mathrm{s})$, and $\mathrm{m}$ represents the combined mass of two electrodes $(\mathrm{g})$. Under $1 \mathrm{mAg}^{-1}$ current density of, the highest $\mathrm{C}_{\mathrm{m}}$ calculated was $153.6 \mathrm{Fg}^{-1}$.

Energy $\left(\mathrm{E}, \mathrm{Wh} \mathrm{kg}^{-1}\right)$ and power $\left(\mathrm{P}, \mathrm{Wkg}^{-1}\right)$ densities are critical parameters for the supercapacitor applications. The following equations can be used to calculate $\mathrm{E}$ and $\mathrm{P}$ :

$E=\frac{1}{8} C_{m} x(\Delta V)^{2}$

$P=\frac{E}{\Delta t}$

Where $\mathrm{C}_{\mathrm{m}}$ is the specific capacitance, $\Delta \mathrm{V}$ represents the potential window $(\mathrm{V})$ and $\Delta \mathrm{t}$ represents the discharge time $(\mathrm{h})$. At a power density of $102.07 \mathrm{Wkg}^{-1}$, the energy density of the graphene hydrogel reaches $49.22 \mathrm{Whkg}^{-1}$ at $1 \mathrm{mAg}^{-1}$, whereas at a power density of $3.47 \mathrm{kWkg}^{-1}$, it stays at $3.43 \mathrm{Whkg}^{-1}$ at $20 \mathrm{mAg}^{-1}$.
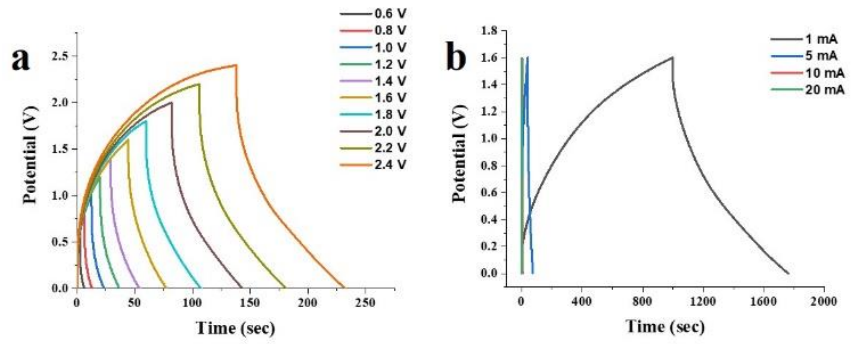

Figure 3. GCD curves of the graphene hydrogel (a) at different potential windows and (b) different current density in $1 \mathrm{M} \mathrm{H}_{2} \mathrm{SO}_{4}$.

The electrochemical stability of all-solid-state supercapacitor electrode materials is a critical factor. The constructed all-solidstate symmetric supercapacitor's long-term electrochemical stability, as measured by GCD over 1000 cycles at a current density of $5 \mathrm{mAg}^{-1}$, was greater than $97 \%$, as illustrated in Figure 4a. The GCD curves before and after 1000 GCD cycles are shown in Figure $\mathbf{4 b .}$
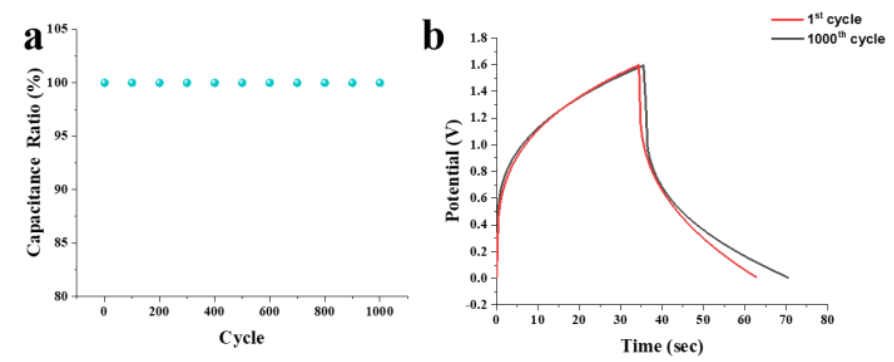

Figure 4. (a) Capacitance retention of the symmetric supercapacitor over 1000 cycles of GCD at current density of $5 \mathrm{mAg}^{-1}$ and (b) the corresponding GCD curves.

\section{Conclusions and Recommendations}

In this work, we have developed a hydrogel made of graphenechitosan composite which was crosslinked using a crosslinker and used it to construct an all-solid-state symmetric supercapacitor. In the composite, chitosan acts as stabilizer as well as electrolyte. The supercapacitor showed a high $\mathrm{C}_{\mathrm{m}}$ value of $153.6 \mathrm{Fg}^{-1}$ at $1 \mathrm{mAg}^{-1}$ current density. Moreover, the all-solidstate symmetric supercapacitor showed an excellent long-term stability which was assessed using GCD curves over 1000 cycles at a current density of $5 \mathrm{mAg}^{-1}$. The results suggest that hydrogel-based supercapacitor may have a great potential in energy-storage applications.

\section{Acknowledge}

The authors have declared no conflicts of interest.

\section{References}

Bashir, S., Hasan, K., Hina, M., Ali Soomro, R., Mujtaba, M. A., Ramesh, S., ... Manikam, R. (2021). Conducting polymer/graphene hydrogel electrodes based aqueous smart Supercapacitors: A review and future prospects. Journal of Electroanalytical Chemistry. Retrieved from https://doi.org/10.1016/j.jelechem.2021.115626

Bonaccorso, F., Lombardo, A., Hasan, T., Sun, Z., Colombo, L., \& Ferrari, A. C. (2012). Production and processing of graphene and 2d crystals. Materials Today. Retrieved from https://doi.org/10.1016/S1369-7021(13)70014-2

Borenstein, A., Hanna, O., Attias, R., Luski, S., Brousse, T., \& Aurbach, D. (2017). Carbon-based composite materials for supercapacitor electrodes: A review. Journal of Materials Chemistry A. Retrieved from https://doi.org/10.1039/c7ta00863e

Bose, S., Kuila, T., Mishra, A. K., Rajasekar, R., Kim, N. H., \& Lee, J. H. (2012). Carbon-based nanostructured materials and their composites as supercapacitor electrodes. Journal of Materials Chemistry. Retrieved from https://doi.org/10.1039/c1jm14468e

Cao, X., Jiang, C., Sun, N., Tan, D., Li, Q., Bi, S., \& Song, J. (2021). Recent progress in multifunctional hydrogel-based supercapacitors. Journal of Science: Advanced Materials and Devices. Retrieved from https://doi.org/10.1016/j.jsamd.2021.06.002

El-Gendy, D. M., Ghany, N. A. A., El Sherbini, E. E. F., \& Allam, N. K. (2017). Adenine-functionalized Spongy Graphene for Green and High-Performance Supercapacitors. Scientific Reports, 7. Retrieved from https://doi.org/10.1038/srep43104 
He, W., Wang, C., Zhuge, F., Deng, X., Xu, X., \& Zhai, T. (2017). Flexible and high energy density asymmetrical supercapacitors based on core/shell conducting polymer nanowires/manganese dioxide nanoflakes. Nano Energy, 35, 242-250. Retrieved from https://doi.org/10.1016/j.nanoen.2017.03.045

Hu, N., Zhang, L., Yang, C., Zhao, J., Yang, Z., Wei, H., ... Xu, Z. J. (2016). Three-dimensional skeleton networks of graphene wrapped polyaniline nanofibers: An excellent structure for high-performance flexible solid-state supercapacitors. Scientific Reports, 6. Retrieved from https://doi.org/10.1038/srep19777

Ke, Q., \& Wang, J. (2016). Graphene-based materials for supercapacitor electrodes - A review. Journal of Materiomics. $\quad$ Retrieved from https://doi.org/10.1016/j.jmat.2016.01.001

Khalid, M., Quispe, L. T., Pla Cid, C. C., Mello, A., Tumelero, M. A., \& Pasa, A. A. (2017). The synthesis of highly corrugated graphene and its polyaniline composite for supercapacitors. New Journal of Chemistry, 41(11), 46294636. Retrieved from https://doi.org/10.1039/c7nj00024c

Khazaeli, A., Godbille-Cardona, G., \& Barz, D. P. J. (2020). A Novel Flexible Hybrid Battery-Supercapacitor Based on a Self-Assembled Vanadium-Graphene Hydrogel. Advanced Functional Materials, 30(21). Retrieved from https://doi.org/10.1002/adfm.201910738

Lai, L., Chen, L., Zhan, D., Sun, L., Liu, J., Lim, S. H., ... Lin, J. (2011). One-step synthesis of NH2-graphene from in situ graphene-oxide reduction and its improved electrochemical properties. Carbon, 49(10), 3250-3257. Retrieved from https://doi.org/10.1016/j.carbon.2011.03.051

Mao, S., Yu, K., Chang, J., Steeber, D. A., Ocola, L. E., \& Chen, J. (2013). Direct growth of vertically-oriented graphene for field-effect transistor biosensor. Scientific Reports, 3. Retrieved from https://doi.org/10.1038/srep01696

Sadak, O. (2021). One-pot scalable synthesis of rGO/AuNPs nanocomposite and its application in enzymatic glucose biosensor. Nanocomposites, 7(1), 44-52. Retrieved from https://doi.org/10.1080/20550324.2021.1917837

Sadak, O., Prathap, M. U. A., \& Gunasekaran, S. (2019). Facile fabrication of highly ordered polyaniline-exfoliated graphite composite for enhanced charge storage. Carbon, 144, 756763.

Retrieved

from https://doi.org/10.1016/j.carbon.2018.12.062

Sadak, O., Sundramoorthy, A. K., \& Gunasekaran, S. (2017). Highly selective colorimetric and electrochemical sensing of iron (III) using Nile red functionalized graphene film. Biosensors and Bioelectronics, 89, 430-436. Retrieved from https://doi.org/10.1016/j.bios.2016.04.073

Sadak, O., Sundramoorthy, A. K., \& Gunasekaran, S. (2018). Facile and green synthesis of highly conductive graphene paper. Carbon, 138, 108-117. Retrieved from https://doi.org/10.1016/j.carbon.2018.05.076

Sadak, O., Wang, W., Guan, J., Sundramoorthy, A. K., \& Gunasekaran, S. (2019). MnO2 Nanoflowers Deposited on Graphene Paper as Electrode Materials for Supercapacitors. ACS Applied Nano Materials, 2(12), 4386-4394. Retrieved from https://doi.org/10.1021/acsanm.9b00797

Shan, C., Yang, H., Han, D., Zhang, Q., Ivaska, A., \& Niu, L. (2009). Water-soluble graphene covalently functionalized by biocompatible poly-L-lysine. Langmuir, 25(20), 1203012033. Retrieved from https://doi.org/10.1021/la903265p

Sollami Delekta, S., Smith, A. D., Li, J., \& Östling, M. (2017).
Inkjet printed highly transparent and flexible graphene micro-supercapacitors. Nanoscale, 9(21), 6998-7005. Retrieved from https://doi.org/10.1039/c7nr02204b

Udayan, A. P. M., Sadak, O., \& Gunasekaran, S. (2020). MetalOrganic Framework/Polyaniline Nanocomposites for Lightweight Energy Storage. ACS Applied Energy Materials, 3(12), 12368-12377. Retrieved from https://doi.org/10.1021/acsaem.0c02376

Wang, H., Lin, J., \& Shen, Z. X. (2016). Polyaniline (PANi) based electrode materials for energy storage and conversion. Journal of Science: Advanced Materials and Devices. Retrieved from https://doi.org/10.1016/j.jsamd.2016.08.001

Wang, W., Sadak, O., Guan, J., \& Gunasekaran, S. (2020). Facile synthesis of graphene paper/polypyrrole nanocomposite as electrode for flexible solid-state supercapacitor. Journal of Energy Storage, 30, 101533. Retrieved from https://doi.org/10.1016/j.est.2020.101533

Wu, L., Hao, L., Pang, B., Wang, G., Zhang, Y., \& Li, X. (2017). $\mathrm{MnO} 2$ nanoflowers and polyaniline nanoribbons grown on hybrid graphene/Ni 3D scaffolds by in situ electrochemical techniques for high-performance asymmetric supercapacitors. Journal of Materials Chemistry A, 5(9), 4629-4637. Retrieved from https://doi.org/10.1039/c6ta10757e

Xia, J., Chen, F., Li, J., \& Tao, N. (2009). Measurement of the quantum capacitance of graphene. Nature Nanotechnology, 4(8), 505-509. Retrieved from https://doi.org/10.1038/nnano.2009.177

Xu, Y., Lin, Z., Huang, X., Liu, Y., Huang, Y., \& Duan, X. (2013). Flexible solid-state supercapacitors based on threedimensional graphene hydrogel films. ACS Nano, 7(5), 4042-4049. Retrieved from https://doi.org/10.1021/nn4000836

Xu, Y., Lin, Z., Huang, X., Wang, Y., Huang, Y., \& Duan, X. (2013). Functionalized graphene hydrogel-based highperformance supercapacitors. Advanced Materials, 25(40), 5779-5784. Retrieved from https://doi.org/10.1002/adma.201301928

Xu, Y., Lin, Z., Zhong, X., Huang, X., Weiss, N. O., Huang, Y., \& Duan, X. (2014). Holey graphene frameworks for highly efficient capacitive energy storage. Nature Communications, 5. Retrieved from https://doi.org/10.1038/ncomms5554

Xu, Y., Sheng, K., Li, C., \& Shi, G. (2010). Self-assembled graphene hydrogel via a one-step hydrothermal process. ACS Nano, 4(7), 4324-4330. Retrieved from https://doi.org/10.1021/nn101187z

Xue, G., Zhong, J., Cheng, Y., \& Wang, B. (2016). Facile fabrication of cross-linked carbon nanofiber via directly carbonizing electrospun polyacrylonitrile nanofiber as high performance scaffold for supercapacitors. Electrochimica Acta, 215, 29-35. Retrieved from https://doi.org/10.1016/j.electacta.2016.08.063

Zhang, Li, \& Zhao, X. S. (2009). Carbon-based materials as supercapacitor electrodes. Chemical Society Reviews, 38(9), 2520-2531. Retrieved from https://doi.org/10.1039/b813846j

Zhang, Liling, Huang, D., Hu, N., Yang, C., Li, M., Wei, H., ... Zhang, Y. (2017). Three-dimensional structures of graphene/polyaniline hybrid films constructed by steamed water for high-performance supercapacitors. Journal of Power Sources, 342, 1-8. Retrieved from https://doi.org/10.1016/j.jpowsour.2016.11.068. 